\title{
SYNTHESIS AND STRUCTURAL, MORPHOLOGICAL AND MAGNETIC CHARACTERIZATION OF THE SUPERCONDUCTING Zr1-xNbXB2
}

Marques, M. D. R. ${ }^{1,2}$; Correa, L. E. ${ }^{3}$; Renosto, S. T. ; Portela, F. S. ${ }^{2}$; Corredor, L. T. ${ }^{4}$; Machado, A. J. S. ${ }^{3}$; Aguiar, J. A. ${ }^{4,1, *}$

${ }^{1}$ PPGMtr-UFPE, Recife-PE, Brazil

2 INFES/PEB- UFF, Santo Antônio de Pádua- RJ, Brazil

${ }^{3}$ EEL, Universidade de São Paulo, Lorena, SP, Brazil

${ }^{4}$ DF-UFPE, Recife-PE, Brazil

*albino@df.ufpe.br

\begin{abstract}
Since the recent discovery of Akimitsu [1] of superconductivity in $\mathrm{MgB}_{2}$ at $39 \mathrm{~K}, \mathrm{MB}_{2}$ materials ( $\mathrm{M}=$ Transition Metal) with the same prototype structure as $\mathrm{MgB}_{2}$ are considered as candidates for multiband superconductivity. This discovered motivated the investigation to search for superconductivity in similar systems. Binary diborides can crystallize in different structure types, although the great majority are those presenting the AlB2-type structure (P6/ mmm space group, number 191) [2]. Although many compounds of $\mathrm{MB}_{2}$ can crystallize in the $\mathrm{AlB}_{2}$ type structure, superconductivity in this class of material is relatively rare. For example, the $\mathrm{ZrB}_{2}$ which crystallizes in the $\mathrm{AlB}_{2}$ prototype structure, does not presents superconductivity. Recently we showed that small $\mathrm{V}$ doping at $\mathrm{Zr}$ site in $\mathrm{ZrB}{ }_{2}$ leads to superconductivity [4]. In this work, we present structural, micro structural, electrical and magnetic studies on $\mathrm{Zr}_{1-\mathrm{x}} \mathrm{Nb}_{\mathrm{x}} \mathrm{B}_{2}$, with $0 \leq x \leq 0$.5. Polycrystalline samples of $\mathrm{Zr}_{1-\mathrm{x}} \mathrm{Nb}_{\mathrm{x}} \mathrm{B}_{2}$ were prepared by arc-melting. The $\mathrm{X}$-ray diffraction patterns were analyzed by Rietveld refinement, allowing the identification of single-phased compounds. The materials were characterized by Scanning Electronic Microscopy (SEM). The SEM micrographs with EDS analysis showed that the presents a uniform composition. Specific heat, magnetization and resistivity measurements confirmed that all prepared samples were superconducting.
\end{abstract}

This work was supported by CAPES, CNPq, FAPESP and FACEPE.

1. J. Nagamatsu et al., Nature 410, 63 (2001).

2. A.S. Pereira,et al., J. Phys. Cond. Mat., 14, 10615 (2002).

3. S. T. Renosto, et al., Phys. Rev. B 87, 174502 (2013). 